\title{
Los crímenes de sistema y el futuro del orden internacional ${ }^{1}$
}

System crimes and the future of the International Law

Crimes do sistema e futuro do Direito

Internacional

sur les crimes du système et l'avenir du droit international

制度的犯罪和国际法的未来

\section{Luigi Ferrajoli ${ }^{2}$ | Universidad de Roma III}

Revista Derechos en Acción ISSN 2525-1678/ e-ISSN 2525-1686

Año 4/No 12 Invierno 2019 (21 junio a 20 septiembre), 27-47

DOl: https://doi.org/10.24215/25251678e299

Recibido: 25/06/2019

Aprobado: 26/06/2019

Resumen: El presente trabajo tiene como objeto denunciar la tensión existente entre la desproporcionada expansión de los efectos de un modelo global que trae consigo la masificación de situaciones mortales para la población vulnerable en el mundo. Asimismo la revisión del crimen como término circunscripto y limitado a las conductas desviadas, para expandir la categoría hacia los crímenes de sistema, para describir a los sujetos activos internacionales que producen situaciones proclives

\footnotetext{
1 Traducción de Nicolás Guzmán (UBA). Conferencia expuesta el 10 de diciembre de 2018 en el congreso organizado por la Fondazione Basso en Roma, Montecitorio, sobre "Derechos humanos y derechos de los pueblos, entre políticas de potencia y derecho internacional", en ocasión del septuagésimo aniversario de la Declaración Universal de los Derechos Humanos.

2 Luigi Ferrajoli (n. Florencia, Italia, 6 de agosto de 1940) es un jurista italiano y luego nacionalizado francés, uno de los principales teóricos del garantismo jurídico, teoría que desarrolló inicialmente en el ámbito del Derecho penal, pero que considera, en general, un paradigma aplicable a la garantía de todos los derechos fundamentales.
} 
a la violación de los derechos humanos de dichos pueblos. El autor se pregunta por ¿cómo debemos llamar a las violaciones masivas de los derechos humanos, consistentes, todas ellas, en catástrofes humanitarias? ¿Cómo debemos calificar, sobre la base de las cartas constitucionales e internacionales de los derechos de libertad y de los derechos sociales que integran nuestros ordenamientos, a los millones de muertos a causa del hambre, la sed y las enfermedades, víctimas del crecimiento exponencial de la desigualdad y la pobreza? ¿Cómo debemos configurar jurídicamente a las cientos de miles de personas que son constreñidas a escapar de las guerras y la miseria provocadas por las políticas de los países más fuertes, que hasta pierden la vida en sus tremendas odiseas o que, al arribar a nuestros países, se topan con la exclusión y la opresión racista solo por sus identidades diferentes? Más aún: ¿cómo debemos concebir, en el plano jurídico, a las devastaciones ambientales que sufren, sobre todo, las poblaciones de los países pobres y que son producidas por la ausencia de límites y controles sobre el desarrollo industrial ecológicamente insostenible de los países ricos?. Por último aborda la cuestión relativa al interés de todos en la supervivencia de la humanidad y en la habitabilidad del planeta.

Palabras claves: Globalización, Soberanía, Orden Internacional, Crímenes de Sistema, Carta di Algeri de los derechos de los pueblos

Abstract: The aim of this work is to report the tension of the disproportionate expansion of the effects of a global model that brings the massification of mortal situations for the vulnerable population in the world. Also, the review of crime as a term circumscribed and limited only to deviant behaviors, in order to expand the category towards system crimes, to describe international active subjects that produce situations which facilitate the violation of the human rights of these peoples. The author wonders how we should call the massive violations of human rights, consistent, all of them, in humanitarian catastrophes? How should we qualify, on the basis of the constitutional and international letters of the rights of freedom and the social rights that make up our ordinances, to the millions of deaths due to hunger, thirst and disease, of victims of the exponential growth of inequality and poverty? How should we legally define the hundreds of thousands of people who are constrained to escape the wars and misery caused by the policies of the strongest countries, who get to even lose their lives in their tremendous odyssey 
or who, when arriving in our countries, face exclusión and racist oppression only because of their different identities? Moreover, how should we conceive, in a legal sleight, the environmental devastation suffered, above all, by the populations of poor countries, which are produced by the lack of limits and controls on the ecologically unsustainable industrial development of the rich countries? Finally, it addresses the issue of everyone's interest in the survival of humanity and the habitability of the planet.

Keywords: Globalization, Sovereignty, International Order, System Crimes, Carta di Algeri of the rights of people.

Resumo: 0 presente trabalho tem como objeto denunciar a tensão existente entre a expansão desproporcional dos efeitos de um modelo global que traz consigo a massificação de situações mortais para a população vulnerável no mundo. Da mesma forma, a revisão do crime como um termo circunscrito e limitado a comportamentos desviantes, para expandir a categoria em direção a crimes sistêmicos, para descrever aos sujeitos ativos internacionais que produzem situações propensas à violação dos direitos humanos desses povos. 0 autor se pergunta por: Como devemos chamar as violações maciças dos direitos humanos, consistentes, todas elas, em catástrofes humanitárias? Como devemos qualificar, com base nas cartas constitucionais e internacionais dos direitos de liberdade e dos direitos sociais que nossos sistemas de regulação, aos milhões de mortes devidas a fome, sede e doenças, vítimas do crescimento exponencial da desigualdade e pobreza? Como devemos configurar legalmente as centenas de milhares de pessoas que estão constrangidas a escapar das guerras e da miséria causadas pelas políticas dos países mais fortes, que até perdem a vida em sua tremenda odisseia ou que, ao chegar em nossos países, eles encontram exclusão e opressão racista só por suas diferentes identidades? Mais ainda, como devemos conceber, no plano legal, as devastações ambientais que sofrem, sobretudo, as populações dos países pobres e que são produzidas pela ausência de limites e controles sobre 0 desenvolvimento industrial ecologicamente insustentável dos países ricos? Finalmente, aborda a questão do interesse de todos na sobrevivência da humanidade e na habitabilidade do planeta.

Palavras-chave: Globalização, Soberania, Ordem Internacional, Crimes do Sistema, Carta di Algeri dos direitos dos povos. 
Résumé: Cet article a pour but celui de dénoncer la tension qui presente l'extension disproportionnée des effets d'un modèle global qui entraîne la massification de situations mortelles pour la population vulnérable du monde. Aussi, on veut revoir l'expression "crime», car il est considérée comme un terme circonscrit et limité aux comportements déviants, afin d'élargir la catégorie aux crimes systémiques et de décrire les sujets actifs au niveau international qui produisent des situations susceptibles de violer les droits fondamentaux de ces peuples. L'auteur se demande comment nous devrions appeler les violations massives des droits de I'homme, qui sont tous compatibles avec les catastrophes humanitaires? Comment qualifier, sur la base des lettres constitutionnelles et internationales des droits de la liberté et des droits sociaux qui composent nos ordonnances, les millions de décès produits pour la faim, la soif et la maladie, victimes de la croissance exponentielle de l'inégalité et de la pauvreté? Comment configurer légalement les centaines de milliers de personnes contraintes d'échapper aux guerres et à la misère causées par la politique des pays les plus forts, qui perdent même la vie dans leur formidable odyssée ou qui, en arrivant dans nos pays affrontent l'exclusion et l'oppression raciste uniquement à cause de leurs identités différentes? En outre, comment devrions-nous concevoir, sur le plan juridique, les ravages environnementaux subis avant tout par les populations des pays pauvres et qui résultent de l'absence de limites et de contrôles sur le développement industriel écologiquement non durable des pays riches? Finalement, on aborde la question de l'intérêt de chacun pour la survie de l'humanité et l'habitabilité de la planète.

Mot-clés: Mondialisation, Souveraineté, Ordre International, Crimes Système, Carta di Algeri des droits des peuples.

摘要: 摘要:本文的目的是谴责全球模式的影响不成比例地扩大之间 的紧张关系, 这种模式带来了世界上弱势群体的致命情境的大规模 化。同样, 将犯罪作为一个受限制的术语进行审查, 并限于不正常的 行为，将类别扩大到系统犯罪，描述产生易于侵犯这些人民人权的 情况的国际活动主体. 提交人想知道为什么我们应该在人道主义灾 难中将所有人的大规模侵犯人权行为称为一贯的? 我们应该如何根 据自由权利的宪法和国际信件以及构成我们条例的社会权利, 对数 百万因饥饿，口渴和疾病造成的死亡，以及指数增长的受害者的资 格进行限定。不平等和贫困? 我们应该如何合法地配置成千上万的 人，他们被迫逃脱最强国家政策所造成的战争和苦难，他们甚至在 
极大的冒险中丧生，或者在抵达我们国家时他们是否因为身份不同 而遭遇排斥和种族主义压迫? 此外，我们应该如何在法律层面上设 想由贫穷国家的人民所遭受的环境破坏，这种破坏是由于对富国的 生态上不可持续的工业发展缺乏限制和控制而产生的?。最后, 它解 决了每个人对人类生存和地球可居住性感兴趣的问题。

关键字: 关键字: 全球化, 主权, 国际秩序, 制度犯罪, Carta di Algeri 的人民权利

\section{La decadencia del paradigma constitucional a nivel internacional}

En todo el Occidente capitalista estamos asistiendo a un triunfo de las derechas y a un vistoso proceso deconstituyente del derecho internacional. En estos años se ha producido la decadencia y, quizás, el ocaso, del proyecto de refundación constitucional del orden internacional sobre la base de los principios de la paz y de la garantía de los derechos fundamentales, establecidos en la Carta de la ONU y en tantas otras cartas y declaraciones de derechos. Uno de los factores de esta decadencia es el resurgimiento de los nacionalismos -aquellos que, en su versión populista, son denominados "soberanismos"-, que han demostrado ser, más allá de su aparente oposición, los aliados más firmes del liberalismo actual. En efecto, son los actuales populismos soberanistas los que se oponen a la puesta en marcha del proyecto de constitucionalización del orden internacional. Defendiendo una perdida $-y$ ya ilusoria- soberanía nacional, ellos son los principales adversarios de la construcción de una esfera pública supranacional, al menos europea, y del desarrollo de un constitucionalismo global que esté a la altura de esos nuevos soberanos absolutos, invisibles e irresponsables, en que se han transformado los mercados.

La estipulación, en cartas y convenciones internacionales, de los principios de igualdad y de dignidad de las personas $\mathrm{y}$ de los derechos fundamentales, tanto de libertad como sociales, requería de la construcción de una esfera pública 
que estuviera a la altura de los poderes salvajes del mercado global, es decir, requería de acuerdos de actuación a través de la introducción de las garantías respectivas: prohibiciones de lesión de los derechos de libertad, obligaciones de prestación (impuestas por los derechos sociales a la salud, la educación y la subsistencia) y garantías jurisdiccionales contra las violaciones de unas y otras. En efecto, a diferencia de lo que sucede con los derechos patrimoniales, las garantías de los derechos fundamentales no se producen de manera simultánea con su declaración, sino que requieren de la construcción -por parte de la política- de sus garantías y de las respectivas funciones e instituciones de garantía. Salvo la institución de la Corte Penal Internacional para los crímenes contra la humanidad, a la cual, de todos modos, no han adherido las potencias más grandes, poco o nada se ha hecho. De esta manera, progresivamente se fue empañando la memoria de los "nunca más" que en el trienio 1945-1948 se opusieron a los horrores de los totalitarismos y las guerras.

Estas enormes violaciones a los derechos fundamentales son, principalmente, producto de la actual globalización, la cual ha alcanzado a los mercados y a la economía pero no a la política ni al derecho. A aquélla le siguió la asimetría entre el carácter global de la economía y las finanzas y el carácter aún estatal de la política y el derecho y, consiguientemente, el vuelco de la relación entre política y economía, en virtud del cual ya no son los gobiernos ni los parlamentos los que dictan las reglas de la economía, sino al revés. Así, se entiende hasta qué punto la ausencia de una esfera pública que esté en condiciones de imponer límites, vínculos y controles a los mercados, ha determinado la soberanía tendencialmente absoluta de los poderes económicos y financieros y el carácter sistémico $\mathrm{y}$, al mismo tiempo, masivo de las consiguientes violaciones de los derechos humanos, cuyo rasgo característico consiste en el hecho de que sus víctimas ya no son individuos singularmente determinados, sino, más bien, pueblos enteros y, en algunos casos, como en las agresiones al ambiente, la humanidad toda. 
Le debemos a Lelio Basso la formulación, en la Carta di Algeri de los derechos de los pueblos, promovida por el nombrado el 4 de julio de 1976, del nexo de recíproca implicación existente entre derechos de cada uno y derechos de todos, entre derechos de las personas y derechos de los pueblos. "El respeto de los derechos del hombre", afirma el preámbulo de la Carta di Algeri, "implica el respeto de los derechos de los pueblos". Es un nexo que hoy es todavía más actual y evidente que en los años Setenta. En efecto, nunca como hoy, en la era de la globalización, los derechos de cada uno se han encontrado tan amenazados y anulados por las agresiones cometidas contra los derechos de pueblos enteros, provenientes de esos soberanos globales y salvajes que son los mercados. Y nunca como hoy la garantía y defensa de los derechos de los pueblos constituyó la principal condición de efectividad de los derechos individuales de las personas.

Naturalmente, en los cuarenta y dos años que han pasado desde que fue formulada la Carta di Algeri, el orden político y jurídico del planeta cambió profundamente. Hace ya un tiempo que, gracias a las luchas de liberación que se llevaban adelante precisamente en aquélla época, ha concluido el proceso de descolonización. Con el constitucionalismo rígido de la segunda posguerra y con la subordinación a la ley de aquel último residuo de gobierno de los hombres que había sido la omnipotencia de las mayorías parlamentarias, el paradigma del Estado de derecho se hallaba completo y perfeccionado. Pues bien, en el momento mismo en que, con el nacimiento de los nuevos Estados post-coloniales, fue exportado a todo el mundo, el Estado soberano e independiente perdió gran parte de sus poderes y mostró ser, a causa del carácter solo nacional de sus esferas públicas, directamente funcional a la soberanía global de los mercados. No desaparecieron, sino que solo cambiaron, las "formas de imperialismo" y de "opresión" de los pueblos a las que hace referencia la Carta de Algeri en su preámbulo. Las desigualdades, opresiones y violencias sobre los pueblos y los crímenes contra la humanidad no disminuyeron en absoluto. 
Al contrario, a despecho de la igualdad en los derechos proclamada en las cartas y pactos internacionales, las desigualdades en las condiciones concretas de vida alcanzaron, en estos años, dimensiones que no tienen precedentes en la historia y que continúan creciendo de manera exponencial. Elena Granaglia ha expuesto los datos terribles de las desigualdades y de su crecimiento exponencial: los pobres son cada vez más pobres y los ricos son cada vez más ricos. Piénsese solo en el dato más escandaloso, extraído del Reporte OXFAM de 2017: las ocho personas más ricas del mundo tienen una riqueza igual a la que posee la mitad más pobre de la población mundial, es decir tres mil quinientos millones de personas. Lo que es más alarmante es el hecho de que el número de esos multimillonarios se ha reducido enormemente en pocos años: eran 62 en 2016, 85 en 2014, 258 en 2005. Gracias a la crisis económica, de la que se han beneficiado ampliamente, estos super-ricos aumentaron su riqueza en los últimos siete años un $44 \%$, mientras que la de la mitad más pobre del mundo disminuyó un $41 \%$. Consiguientemente, la movilidad social no se bloqueó, sino que cambió su dirección: ya no es desde abajo hacia arriba, sino desde abajo hacia condiciones salariales y de vida todavía más bajas.

Por lo tanto, no han disminuido las opresiones y las violaciones de los derechos de los pueblos; las que han cambiado y se volvieron todavía más extensivas y voraces, son las formas del dominio y la opresión. El dominio político del "imperialismo", evocado en el preámbulo de la Carta de Algeri, fue sustituido por el dominio económico del mercado en la globalización actual. El viejo colonialismo, consistente en el sometimiento material y militar de los pueblos más débiles, fue sustituido por un neo-colonialismo de tipo económico y financiero y por la subordinación de todos los pueblos a una suerte de nueva soberanía, impersonal y privada, de los aludidos mercados. Los viejos golpes de estado militar fueron reemplazados por las disgregaciones de las subjetividades colectivas, la pasivización de los electores -movilizados contra el diverso, como lo es típicamente el inmigrante- y las autocracias electivas, 
como las denominó Michelangelo Bovero, en las que se han transformado las democracias representativas. Mientras tanto, a la finalización de la guerra fría entre bloques contrapuestos le ha seguido, en este último cuarto de siglo, el retorno de la guerra caliente como instrumento de solución de los problemas internacionales. Finalmente, las migraciones actuales nos colocan frente a una doble violación masiva de los derechos humanos, producida por otras tantas políticas de muerte: las masas de desesperados que huyen de la miseria, el hambre y los trastornos climáticos provocados por las políticas y por el desarrollo industrial de los países ricos, se encuentran luego en estos mismos países con prácticas de exclusión, opresión y discriminación ejecutadas por las políticas xenófobas y racistas de nuestros gobiernos. En suma, la distancia entre el "deber ser" diseñado por las cartas de los derechos y el "ser" efectivo del derecho internacional se ha agrandado vistosamente.

\section{Crímenes de sistema}

Frente a esta creciente distancia, se presenta una cuestión teórica de fondo, que ya afrontamos en ocasión del congreso realizado dos años atrás, a propósito de los cuarenta años de la Carta di Algeri, pero que, me parece, amerita una ulterior profundización. La cuestión se refiere al estatuto jurídico de tal distancia. Son dos las preguntas que, al respecto, cabe formular.

La primera serie de preguntas, de carácter teórico, es la siguiente: ¿cómo debemos llamar a las violaciones masivas de los derechos humanos, consistentes, todas ellas, en catástrofes humanitarias? ¿Cómo debemos calificar, sobre la base de las cartas constitucionales e internacionales de los derechos de libertad y de los derechos sociales que integran nuestros ordenamientos, a los millones de muertos a causa del hambre, la sed y las enfermedades, víctimas del crecimiento exponencial de la desigualdad y la pobreza? ¿Cómo debemos configurar jurídicamente a las cientos de miles de personas que son constreñidas a escapar de las guerras y la miseria provocadas por 
las políticas de los países más fuertes, que hasta pierden la vida en sus tremendas odiseas o que, al arribar a nuestros países, se topan con la exclusión y la opresión racista solo por sus identidades diferentes? Más aún: ¿cómo debemos concebir, en el plano jurídico, a las devastaciones ambientales que sufren, sobre todo, las poblaciones de los países pobres y que son producidas por la ausencia de límites y controles sobre el desarrollo industrial ecológicamente insostenible de los países ricos?

Ciertamente, estas catástrofes no son configurables como crímenes en sentido penal. Al igual que sus víctimas, identificables con pueblos enteros o incluso con la humanidad toda, sus autores tampoco son identificables con personas singularmente determinadas, sino más bien con los mecanismos del sistema económico y político. Además, al igual que lo que sucede con los efectos catastróficos masivos, no identificables en eventos dañosos singulares y determinados, tampoco las acciones -ellas también masivas- son identificables en comportamientos determinados, de modo que pudieran ser prefiguradas como delictivas, pues conforman conjuntos complejos de actividades políticas y económicas realizadas por una pluralidad indeterminada y no determinable de sujetos. En pocas palabras, se trata de agresiones a los derechos de las personas que no pueden ser enfrentadas con los principios garantistas del derecho penal: ni con el principio de la responsabilidad personal, ni con el principio de legalidad ni con el de certeza de los tipos penales.

Sin embargo, estas catástrofes, que equivalen a enormes violaciones de los derechos fundamentales estipulados en las cartas nacionales y supranacionales, no son fenómenos naturales: no lo son los millones de muertos por hambre, sed y enfermedades no curadas; no lo son los cataclismos ni las devastaciones ambientales provocadas por el actual desarrollo industrial ecológicamente insostenible; tampoco lo son las omisiones de auxilio que cada año se cobran como víctimas a miles de inmigrantes que intentan ingresar a nuestros países. Estas catástrofes tampoco son simples injusticias. Son, en cambio, violaciones gravísimas de los derechos humanos sancionados 
en varias cartas constitucionales e internacionales, cometidas a través de agresiones a pueblos enteros y sus derechos.

Se presenta entonces la segunda serie de preguntas, de carácter meta-teórico. Ante todo, debemos preguntarnos si resulta admisible que la criminología, la ciencia jurídica, la ciencia política y el debate público ignoren o, en todo caso, se muestren desinteresados por estas atrocidades, para nada naturales sino provocadas por el actual anarco-capitalismo global. Debemos preguntarnos si la criminología y el debate político pueden hoy desinteresarse de estas agresiones a los derechos humanos y a los bienes fundamentales, que contrastan con nuestras cartas constitucionales e internacionales y que, por otro lado, en caso de no ser enfrentadas por el derecho y la política a través de la introducción de límites y garantías idóneas y de las funciones e instituciones de garantía conexas, pueden terminar por anular todas nuestras conquistas de civilidad y provocar, más temprano que tarde, la destrucción de la convivencia pacífica y la habitabilidad misma del planeta.

Creo que una respuesta racional a ambas cuestiones requiere de una actualización y una refundación de las categorías teóricas con las que leemos e interpretamos la realidad. Al respecto, se presentan una cuestión teórica y otra epistemológica, ambas de fondo: la primera se refiere a la noción de "crimen"; la segunda tiene que ver con el rol científico y explicativo de la criminología y, por otro lado, de la ciencia jurídica. Está claro que la palabra "crimen" reviste una fuerte capacidad de estigmatización moral, social y política. Pues bien, la criminología tradicional y el debate público siempre han sido subalternos al derecho penal, habiendo concebido y tematizado como "crímenes" únicamente a los comportamientos desviados previstos como delitos por el derecho penal. De este modo, tanto las ciencias jurídicas y sociales como el debate público han desarrollado y continúan desarrollando un doble efecto de legitimación ideológica: por un lado, la descalificación, como injustos y moralmente reprobables, únicamente de los hechos previstos como delitos por nuestros sistemas penales y, por el 
otro, la legitimación como justos, o al menos como permitidos y no injustos, de todos los hechos no configurados como delitos. Así, se ha producido, sobre todo en estos últimos años, un singular acomodamiento -en el debate público y en el sentido común- del juicio jurídico, político y moral únicamente a los parámetros ofrecidos por el derecho penal. Solo los hechos previstos y juzgados como delictivos, es decir como crímenes en sentido penal, suscitan la indignación y estigmatización moral y política. Todo lo que no está prohibido como delito está concebido como permitido. De esta manera, fenómenos incomparablemente más graves y catastróficos que los delitos, tales como los que he recordado más arriba, justamente porque no son tratados ni son tratables penalmente, resultan tolerados con resignación o, peor aún, con indiferencia.

La emancipación y la autonomía científica de la criminología y de la ciencia jurídica y, más aún, la autonomía política del debate público, requieren, al contrario, que la previsión de un hecho como delito no sea considerada ni una condición necesaria ni una condición suficiente de su calificación como "crimen". Obviamente no puede ser considerada una condición suficiente -como, ciertamente, jamás la consideró ni siquiera la criminología tradicional-, si tenemos en cuenta que no se pueden concebir como crímenes muchísimos delitos, como los de opinión, las contravenciones y las violaciones del derecho penal burocrático que hoy produce la inflación de la legislación penal. Pero, sobre todo, la previsión de un hecho como delito no puede ser considerada una condición necesaria de su calificación como crimen. Una criminología científica no subalterna a las contingentes elecciones legislativas de política penal, debe concebir como "crímenes", además de a los comportamientos más graves castigados como delitos por el derecho penal, también a los hechos políticos, económicos y sociales que, aun cuando no reconducibles a la responsabilidad penal de personas singulares, están de todos modos en contraste con elementales principios constitucionales formulados en las cartas y convenciones sobre derechos fundamentales que integran nuestros 
ordenamientos. En pocas palabras, estos hechos ingresan en la fenomenología del ilícito jurídico, aunque no del ilícito penal.

Con esto, retomo y aclaro la propuesta que presenté en ocasión del congreso antes recordado del 4 de julio de 2016, de introducir, en nuestro léxico jurídico, una noción de crimen bastante más amplia que aquella de crimen penal. Se trata de colmar una laguna presente en nuestro léxico-jurídico, es decir de dar un nombre a esa otra clase de grandes violaciones de derechos y bienes fundamentales consagrados en las cartas constitucionales o internacionales y que, sin embargo, no consisten, como ocurre con los crímenes penales, en actos individuales productores de eventos dañosos exactamente determinados por la ley e imputables a la responsabilidad de personas también determinadas. La propuesta consiste en incluir, en la noción de "crimen", también a esta clase de violaciones jurídicas, no menos -e, incluso, generalmente más- graves que aquellas violaciones que son perseguidas por el derecho penal: se trata de aquellas que propongo denominar crimenes de sistema y que consisten en agresiones y violaciones de los derechos de los pueblos cometidas a través del ejercicio descontrolado de los poderes globales -políticos, económicos y financieros- y del desarrollo anárquico del capitalismo.

No se trata, obviamente, de los "crímenes de los poderosos", que son siempre crímenes penales, cuya gravedad y tendencial impunidad han sido objeto de investigación en una abundante literatura de criminología crítica. Tampoco se trata de los "crímenes de Estado" o de los "crímenes contra la humanidad", también tratados por el derecho penal internacional luego de esa gran conquista que fue la institución de la Corte Penal Internacional. Los crímenes de sistema, al consistir en violaciones masivas de derechos humanos constitucionalmente establecidos, son seguramente reconducibles a la fenomenología del ilícito jurídico. Sin embargo, no son ilícitos penales, pues carecen de los elementos constitutivos del delito. Sus rasgos distintivos -esto es, aquellos que, empleando la terminología penal, podríamos denominar sus elementos constitutivos- son 
dos: el carácter indeterminado o indeterminable tanto de la acción como del evento, generalmente catastrófico, y el carácter indeterminado y pluri-subjetivo tanto de los autores como de las víctimas, consistentes estas últimas, por lo general, en pueblos enteros o, peor aún, la humanidad toda.

De esta manera, resulta evidente que el reconocimiento como crímenes de sistema de las enormes violaciones de los derechos antes recordadas, cuyas víctimas son tendencialmente pueblos enteros o toda la humanidad, conlleva una ampliación no solo de la esfera de competencia de las jurisdicciones de opinión -como es aquella de nuestro Tribunal permanente de los pueblos- sino también del campo de indagación de las disciplinas ius-internacionalistas. Entre otras cosas, tal reconocimiento debería sugerir la institución de una jurisdicción internacional con poderes de comprobación de los ilícitos, aun cuando careciera del poder de aplicar una sanción. En efecto, la enormidad de estos crímenes de sistema impone a la criminología, la ciencia jurídica, el debate político e incluso a las instituciones internacionales, una emancipación respecto de la subalternidad al derecho penal y de los filtros selectivos y justamente garantistas que identifican a los crímenes penales. Ha sido por causa de esta subalternidad al derecho penal que la criminología tradicional y el debate público terminaron por ignorar, junto a los crímenes de sistema, las responsabilidades políticas, económicas y sociales por los daños provocados por aquéllos a pueblos enteros y, a largo plazo, a toda la humanidad. Es solo porque tales crímenes no son tratados ni pueden ser tratables por la justicia penal (la cual se encuentra atada a los principios garantistas de la responsabilidad individual y de la certeza de los tipos penales), que ellos no generan un escándalo, sino, más bien, la aceptación acrítica -la actual banalización del mal- como si fuesen fenómenos naturales e inevitables. Por esto, la condición prejudicial para afrontar y prevenir estas violaciones es que sean percibidas socialmente como "crímenes", ya no más tolerables por la consciencia civil del mundo: precisamente, como "crímenes de sistema”, para evidenciar su carácter humano e ilícito en cuanto 
contrastan con todos los valores de nuestra civilidad jurídica y, a la vez, para imputarlas a las responsabilidades no penales sino, antes bien, políticas y morales de quienes podrían, gracias a la proyección y a la introducción de garantías de derecho internacional adecuadas, impedirlas o, al menos, reducirlas.

Tomemos las leyes y las prácticas adoptadas en Italia, como en muchos otros países, contra la inmigración clandestina. Leyes y prácticas de este tipo son responsables de la silenciosa masacre producida por los rechazos que, en las fronteras, se producen contra los inmigrantes clandestinos. Se trata de varios miles de víctimas, completamente removidas de nuestra conciencia: más de treinta mil personas en los últimos quince años. Es claro que estas masacres no pueden ser consideradas desastres naturales, sino crímenes de sistema, aun cuando generalmente no resulten punibles como delito las políticas y las leyes que las provocan. Solo así puede, por un lado, desarrollarse la conciencia acerca de su contradicción con todos nuestros valores de civilidad y, por el otro, madurar, en el sentido común y en el debate público, la necesidad de impedir la comisión de aquéllas, por ilícitas.

El mismo discurso puede realizarse respecto de los millones de muertos cada año por hambre, sed, enfermedades y devastaciones ambientales. Hoy, más de ochocientos millones de personas sufren el hambre y la sed y cerca de dos mil millones se enferman sin posibilidad de curarse. La consecuencia es que cada año mueren cerca de ocho millones de personas -veinticuatro mil por día-, en gran parte niños, por la falta de agua potable y de alimentación de base, a causa de la escasez y de las contaminaciones. Todavía más dramática es la situación de la salud. En efecto, otros tantos millones de personas mueren cada año por falta de fármacos salva-vidas: víctimas del mercado más que de las enfermedades, pues los remedios que pueden curarlas son patentados y se vuelven inaccesibles o, peor todavía, se dejan de producir o de distribuir por falta de demanda en los países ricos en los que las enfermedades -tuberculosis, malaria, infecciones respiratorias, sida- han sido erradicadas y prácticamente han desaparecido. 
Tampoco estas tragedias son catástrofes naturales, sino el resultado de crímenes de sistema imputables a los poderes salvajes del mercado, a pesar de que no resulte aplicable ni sea concebible -no obstante los daños incalculables que provocanninguna figura delictiva. En efecto, se trata de una gigantesca omisión de auxilio a poblaciones enteras: por ende, se trata de un doble crimen, consistente, en primer lugar, en las catástrofes producidas y, luego, en la falta de auxilio a las personas y poblaciones golpeadas. Pero está claro que, sin la estigmatización de estos fenómenos como "crímenes de sistema", resulta ilusorio que pueda madurar, en el debate público, algún apoyo a las propuestas de políticas dirigidas a impedirlos.

Finalmente, piénsese en la producción y en el mercado de las armas, responsables de gran parte de los cuatrocientos cincuenta mil homicidios que ocurren cada año en el mundo, de los varios cientos de miles de suicidios e incidentes mortales y de los cerca de dos millones de muertes por año en las guerras que infestan el planeta. Bastaría prohibir las armas -su tenencia, su comercialización y su producción- para concretar, con el monopolio público de la fuerza, el pasaje del estado de naturaleza a la sociedad civil teorizado hace más de tres siglos por Thomas Hobbes y, de este modo, poner fin a esta tragedia, de la cual solo se benefician los fabricantes de armas y la clase política confabulada con -y corrompida por-aquéllos.

\section{Las posibles alternativas a la crisis del derecho internacional}

Llegados a este punto, debemos preguntarnos: ¿qué rol pueden desempeñar el derecho $\mathrm{y}$, antes aún, la política, para afrontar estos crímenes de sistema, los cuales marcan un vacío ya no de derecho penal sino directamente de derecho? La primera condición de una respuesta no renunciataria a esta pregunta es el rechazo de la idea -repetida durante estos años por los gobernantes y por quienes los apoyan- de que no existen alternativas a la actual situación. Esta es una tesis claramente 
ideológica de legitimación de los órdenes existentes. En efecto, no es cierto que no haya alternativas a las actuales políticas. Las alternativas están y consisten, precisamente, en la puesta en marcha -a través de una refundación de la política y la introducción de garantías idóneas- del proyecto de un derecho internacional basado en la paz y en los derechos fundamentales, diseñado por la Carta de la ONU y por las tantas cartas internacionales sobre derechos humanos.

La primera alternativa es la reactivación, desde abajo, de la política y la democracia. Esta es una indicación que también está sugerida en un artículo de nuestra Constitución, que se debe, junto al art. 3 primer apartado, a la obra constituyente de Lelio Basso: se trata del artículo 49, según el cual los ciudadanos "tienen derecho a asociarse libremente en partidos para concurrir, a través del método democrático, a determinar la política nacional". Esta norma nos dice dos cosas. La primera es que la democracia política no consiste simplemente en el consenso o, peor, en el menor disenso respecto de esta o aquella fuerza política, expresado por los ciudadanos en el momento del voto, sino, antes bien, en el hecho de que los ciudadanos "concurran" activamente "a determinar la política nacional". La segunda es que esta participación activa de los ciudadanos en la determinación de la política nacional es posible solo a través de los "partidos", que no son simples máquinas electorales, sino lugares sociales radicados en el territorio, en los cuales, con método democrático, se forma la voluntad popular y se deciden las candidaturas de los representantes y a los cuales estos son llamados a responder por sus acciones. Es sobre la base de estas dos indicaciones que varias veces he propuesto una reforma radical o, al menos, una auto-reforma de los partidos, basada, además de sobre las garantías de la democracia interna, sobre la separación entre representantes y representados, como condición de la misma relación de representación y de responsabilidad política.

La segunda alternativa consiste en la ampliación del paradigma constitucional más allá del Estado, esto es, en su 
expansión en una cuádruple dirección: hacia un constitucionalismo social -junto con el constitucionalismo liberal- a través de la garantía de los derechos sociales y, por ello, como alternativa a las formas burocráticas y paternalistas del Estado social actual; hacia un constitucionalismo de derecho privado, como sistema de límites y vínculos a los actuales poderes salvajes de los mercados, junto al constitucionalismo de derecho público como sistema de límites a los poderes públicos; hacia un constitucionalismo de los bienes fundamentales, desde los bienes comunes hasta los fármacos salva-vidas y a la alimentación básica, junto con el constitucionalismo de los derechos fundamentales; hacia un constitucionalismo supranacional o de derecho internacional, junto con el estatal. Son cuatro expansiones que dicta la lógica misma del constitucionalismo, cuya historia es la de una progresiva ampliación de la esfera de los derechos: de los derechos de libertad en las primeras declaraciones y en las constituciones del Ochocientos, al derecho de huelga y a los derechos sociales en las constituciones del siglo pasado, hasta los nuevos derechos a la paz, al ambiente, a la información, al agua y a la alimentación, que hoy son reivindicados pero que no están todos constitucionalizados. Se ha tratado de una historia social y política, antes que teórica, pues ninguno de estos derechos vino desde arriba, sino que todos fueron conquistados por movimientos revolucionarios: las grandes revoluciones liberales americana y francesa, luego los movimientos del Ochocientos en Europa a favor de los estatutos, después la lucha de liberación antifascista de la cual nacieron las actuales constituciones rígidas y, finalmente, las luchas operarias, feministas, ecologistas y pacifistas del siglo pasado.

Es difícil prever si una ampliación semejante del constitucionalismo y de la democracia logrará desarrollarse o si continuarán prevaleciendo la miopía y la irresponsabilidad de los gobiernos. Los obstáculos para tal expansión lo constituyen, además de los poderosos intereses económicos que se oponen a ella, ciertas aporías de la democracia que han surgido con la actual globalización. Las democracias representativas de 
nuestros países nacieron y permanecen aún ancladas a los Estados nacionales. Por ello, están vinculadas a los tiempos breves, brevísimos, de las competencias electorales o, peor aún, de las encuestas, y a los espacios estrechos de los territorios nacionales: tiempos breves y espacios angostos que, evidentemente, impiden a los gobiernos estatales desarrollar políticas que estén a la altura de los desafíos y problemas globales. De este modo, aquellos que he denominado "crímenes de sistema" y que amenazan al futuro de la humanidad -el hambre, las enfermedades no curadas, las posibles explosiones nucleares, las devastaciones ambientales- son ignorados por la opinión pública y por los gobiernos nacionales y no ingresan en la agenda política, la cual está completamente atada a los estrechos horizontes nacionales diseñados por los eventos electorales. Hay luego una tercera aporía que afecta a nuestras democracias. De manera simultánea a la pérdida de soberanía de los Estados, sustituida por la soberanía invisible e irresponsable de los mercados, en nuestros países están tomando la delantera los movimientos populistas -euro-escépticos, xenófobos, soberanistas y nacionalistas- que, mientras se oponen solo demagógicamente a aquellos nuevos soberanos globales, resultan, en los hechos -tal como he indicado al comienzo-, sus principales aliados, pues se oponen a la única política que se encontraría en condiciones de enfrentarlos: la construcción de una esfera pública a su altura, al menos europea y con perspectiva global, capaz de imponerles reglas, límites y controles.

Esta es, precisamente, la única respuesta racional que la política y el derecho pueden ofrecer a los crímenes de sistema y a la consiguiente crisis de nuestras democracias. Hay dos cosas que son ciertas. La primera se refiere a la alternativa ante la cual se colocó a la humanidad. Hoy, o se va hacia adelante en el proceso constituyente, primero europeo y luego global, sobre la base de la garantía de la paz y de los derechos vitales de todos, o se va hacia atrás, de manera brutal y radical. O se apunta a la integración constitucional y a la unificación política de Europa, quizás a través de una Asamblea constituyente europea, o se 
produce una disgregación de la Unión y un quiebre de nuestras economías y democracias, a favor de los tantos populismos que están creciendo en todos los países miembros. O se imponen límites, en el interés de todos, al desarrollo desregulado y salvaje del capitalismo global, o se va en sentido contrario, hacia un futuro de crímenes de sistema todavía más catastróficos: a devastaciones ambientales como consecuencia de un desarrollo industrial económicamente insostenible; a la amenaza y autodestrucción nuclear de un mundo ya repleto de armas incomparablemente más mortíferas que las de cualquier época anterior; al crecimiento exponencial de la desigualdad, la miseria y el hambre, así como también del crimen organizado y del terrorismo. Cabe añadir que, a diferencia de todas las tragedias pasadas de la historia del hombre, las catástrofes producidas por estos crímenes de sistema son en gran parte irreversibles. Por primera vez en la historia existe el peligro de que, cuando se adquiera conciencia de la necesidad de cambar el rumbo y de hacer frente a tales crímenes, sea demasiado tarde. En pocas palabras, podríamos no llegar a tiempo para formular los nuevos "nunca más".

La segunda certeza se refiere al carácter para nada utópico, sino, al contrario, racional y realista, del proyecto constitucional diseñado por las cartas de los derechos producidas por el constitucionalismo del Novecientos. "La pobreza en el mundo", escribió Thomas Pogge, "es mucho más grande, pero también mucho más pequeña de cuanto nos imaginamos... Su eliminación no requeriría más del $1 \%$ del producto global": precisamente, el 1,13\% del producto bruto interno del mundo, cerca de 500 mil millones de dólares al año, mucho menos que el presupuesto anual para defensa de los Estados Unidos. Por otro lado, hay una gran novedad, positiva, que se generó por la necesidad de proteger a los derechos y bienes fundamentales de los crímenes de sistema y que permite mantener una cuota de optimismo: me refiero a la interdependencia creciente entre todos los pueblos de la tierra, la cual resulta idónea para generar una solidaridad sin precedentes entre todos los seres 
humanos y para refundar la política como política interna del mundo, basada en la existencia -por primera vez en la historia- de un interés público y general mucho más amplio y vital que todos los intereses públicos del pasado: el interés de todos en la supervivencia de la humanidad y en la habitabilidad del planeta, asegurado por límites impuestos a cualquier poder, político y económico, para la garantía de los bienes comunes y de los derechos fundamentales de todos. La alternativa, debemos saberlo, es un futuro de regresión global, signado por el crecimiento de las desigualdades, los cataclismos, los racismos y los miedos y, junto con ellos, la violencia, las guerras, los terrorismos y la inseguridad general. 